\title{
Arbuscular Mycorrhizal Colonization Enhances Biochemical Status in and Mitigates Adverse Salt Effect on Two Legumes
}

\author{
Promita DATTA, Mohan KULKARNI* \\ University of Pune, Department of Chemistry, Division of Biochemistry, Pune-411007, Maharashtra, India; \\ promita.datta.83@gmail.com,drmvkulkarni@gmail.com (*correspondingauthor)
}

\begin{abstract}
Symbiotic association between arbuscular mycorrhizal (AM) species and host plant roots improves plant growth and protects them from several abiotic stress factors. In the present study, the effect of Glomus mosseae and Glomus fasciculatum as an individual inoculation and in combination was studied on two legumes (Glycine max and Cyamopsis tetragonoloba) under soil salinity stress gradient [1.04 (control) to $8.26 \mathrm{dS} / \mathrm{m}$ ]. Individual and co-inoculation of both the AM fungi alleviated adverse salt effect, with improvement in plant dry weight matter and biochemical parameters. However, these two isolates worked better in combination with respect to higher accumulation of soluble carbohydrate, reducing sugar, protein, proline concentration etc. C. tetragonoloba showed better response as compared to G. max in relation to improvement in nutritional profile under salt stress after AM treatment. As compared to non-mycorrhizal counterparts, co-inoculation with $G$. mosseae and $G$. fasciculatum in C. tetragonoloba enhanced total chlorophyll ( $14.83 \%$ at soil salinity of $3.78 \mathrm{dS} / \mathrm{m}$ ), soluble carbohydrate $(17.26 \%$ at soil salinity of $5.94 \mathrm{dS} / \mathrm{m})$, proline $(8.79 \%$ at soil salinity of $3.78 \mathrm{dS} / \mathrm{m})$ while exposed to different soil salinity levels. Also, co-colonization with both the isolates showed more root colonization (\%) and may be responsible for the better effect in salt stress alleviation. Electrolyte leakage of mycorrhizal plants was lowered at soil salinity gradient of 2.10 to 8.26 $\mathrm{dS} / \mathrm{m}$ and hence, maintained membrane stability. These two isolates can be utilized as bio-inoculant in alleviation of adverse salt effect in soil in association with the two test legume plants.
\end{abstract}

Keywords: Cyamopsis tetragonoloba, electrolyte leakage, Glomus fasciculatum, Glomus mosseae, Glycine max, proline, soil salinity stress

\section{Introduction}

Salinization of soil is becoming a severe agricultural constraint in arid and in semi arid regions of India. Presence of excess salt concentrations in soil solution arises mainly due to the heavy use of chemical fertilizers and use of low quality water (during irrigation of agricultural land) which contains soluble salts in large amount (Al-Karaki, 2000; Chartzoulakis and Klapaki, 2000). When salt concentration in soil reaches beyond the normal range, it makes the land unproductive as it results in nutrient imbalance in plants, hampers water availability followed by stunted growth and leads to reduced crop productivity (Al-Karaki et al., 2001; Hopkins and Huner, 1999). Development of salt tolerant crop varieties and physico-chemical methods for removal of excess salts from agricultural soils have been tried (Cuartero and Fernandez-Munoz, 1998; Hamdy, 1990; Hamdy, 1990; Muralev et al., 1997). These approaches have been successful but are costly and hence, a new alternative attempt has taken up to tackle the deleterious effects of saline soils which involve inoculation of salt tolerant arbuscular mycorrhizal (AM) fungi in agricultural crop.

AM fungi are considered as obligate symbionts and are naturally associated with roots of around $90 \%$ vascular plants (Allen, 1991). AM fungi improve plant health by providing essential mineral nutrients from soil. They maintain physiological processes of the host plant, as well as protect it from several biotic and abiotic stresses (Augé, 2000; Ruiz-Lozano, 2003; Sylvia and Williams, 1992). In salt stressed soil, phosphate ions usually precipitate along with $\mathrm{Ca}^{2+}, \mathrm{Mg}^{2+}, \mathrm{Zn}^{2+}$ and are less available to plants (Azcon-Aguiler et al., 1979). But, AM symbiosis in plants enhances the uptake of less mobile phosphorus by extending their external hyphal network beyond nutrient depletion zone. In mitigation of salt stress, AM fungi also improve plant growth, hormonal status, increase nutrient acquisition, maintain osmotic balance, reduce ion toxicity etc. (Juniper and Abbott, 1993; Lindermann, 1994; Ruiz-Lozano, 2003).

With increasing world population, the demand for food, mainly cereal based protein rich diet is increasing, especially in developing countries. Due to scarcity of productive agricultural land and ever increasing population growth, the developing countries are facing the problem of food crisis and hence, protein-rich leguminous food may be one of the substitutes (Sadik, 1991; Weaver, 1994). In such scenario, cultivation of legume plants is promising considering protein content and presence of carbohydrate pool. It is reported that 
382

under abiotic stress condition, improvement of biochemical and antioxidant profile of the host legume plant was observed following colonization with AM fungi (Porcel and Ruiz-Lozano, 2004). Several reports suggest that mycorrhizal inoculation with single AM isolate reduces the detrimental effects of salinity, but salt tolerance level of the plant as well as mycorrhizal efficiency to respond the host varies among different plant species and mycorrhizal fungi (Burke et al., 2003; Tian et al., 2004). Hence, in alleviation of salt stress for particular plant species, selection of specific AM fungi as an individual or in combination of two or more is essential. The interaction between legume plant and combined inoculation of two different AM fungi is not well studied before and hence, the present study was aimed at investigating the individual and combined effects of Glomus mosseae and Glomus fasciculatum on two different crop legumes under soil salinity stress. A comparison between two crop legumes Glycine max and Cyamopsis tetragonoloba was undertaken in relation to improvement in plant growth and biochemical status. $G$. max is considered as inexpensive source of proteins and is also valued for its high oil content. C. tetragonoloba is an annual legume and is an important source of guar gum. Guar gum is directly used in dairy industry and in textile industry after its derivatization. Salt tolerant AM fungi were used in this study as bio-inoculants for cultivation of legumes in salt stressed soil, as both the legumes have nutritional significance.

\section{Materials and methods}

\section{Chemicals}

All the chemicals used in this study were of analytical reagent grade.

\section{Plant Material}

Seeds of $G$. max and $C$. tetragonoloba used in this study were obtained from Naik Seeds Pvt. Ltd., Pune, Maharashtra (India). Seeds were surface sterilized using sodium hypochlorite solution $(0.5 \%$ w/v): reverseosmosis water (1:3), followed by rinsing with reverseosmosis water. Surface sterilized seeds of $G$. max and $C$. tetragonoloba were directly placed on moist filter paper for germination. At first true leaf stage, seedlings of almost equal length were used for transplantation in pot.

\section{Mycorrhizal treatment and experimental design}

$G$. mosseae (Nicol and Gerd) and G. fasciculatum (Thaxt.) Gerd and Trappe used in this study were isolated in the laboratory of University of Pune, earlier from Lonar Crater Lake, Buldhana and Sakri, Dhule, Maharashtra respectively, by wet sieving and decanting method (Datta, 2012; Gerdemann and Nicolson, 1963; Schenck and Perez, 1990). Spores were propagated in Zea mays L. for three months. $G$. mosseae and $G$. fasciculatum soil based inocula contained 150 to 160spores/10 g air-dried soil with AM colonized roots ( $\sim 75 \%$ colonization) and 100 to 110 spores/10 g airdried soil and roots of $\sim 53 \%$ AM colonization respectively. These soil based inocula were used for further study.
Soil used for greenhouse study, contained sand (35\%), slit $(57 \%)$ and clay (8\%) with properties of $\mathrm{pH}: 6.0$, organic matter: $1.3 \%$, available P: $0.75 \mathrm{mg} / 100 \mathrm{~g}$, available $\mathrm{N}: 0.12 \mathrm{mg} / 100 \mathrm{~g}$ and available K: $0.45 \mathrm{mg} /$ $100 \mathrm{~g}$ and was mixed with river sand (particle size of $<0.3$ $\mathrm{mm})(1: 1 \mathrm{v} / \mathrm{v})$. This sand-soil mixture was autoclaved $\left(121^{\circ} \mathrm{C}, 103.4 \mathrm{kPa}\right.$, for $\left.1 \mathrm{~h}\right)$ and used for further study.

The experiment was designed in a complete randomized design, consisted of four mycorrhizal treatments (NM: non-mycorrhizal, Gm: G. mosseae, Gf: $G$. fasciculatum and $G m+G f: G$. mosseae $+G$. fasciculatum), five soil salinity levels [1.04 (control), 2.10, $3.78,5.94$ and $8.26 \mathrm{dS} / \mathrm{m}$ ], two test plants $(G$. max and $C$. tetragonoloba), with five replicates (three plants per replicate). In $G m$ and $G f$ treatment, $50 \mathrm{~g}$ of $G$. mosseae and $75 \mathrm{~g} \mathrm{G}$. fasciculatum soil based inocula were used. However, in $G m+G f$ treatment, $25 \mathrm{~g}$ of $G$. mosseae and $40 \mathrm{~g}$ of $G$. fasciculatum were used. Variable amount of soil based inocula were applied to achieve almost similar number of spores per pot ( $~ 800$ spores/pot). Mycorrhizal treatments were provided by placing respective soil based inoculum $3 \mathrm{~cm}$ below the seedling prior to seedling transplantation. Plants without mycorrhizal inoculum served as non-mycorrhizal control. Sand-soil volume (3 $\mathrm{kg}$ ) was kept constant in all mycorrhizae treated and untreated pots. On every alternate day, plants were irrigated with tap water (sieved through $105 \mu$ sieve) and with Hoagland solution $(\mathrm{X} / 10)$ twice a month (Hoagland and Arnon, 1940). Irrigation was done in such a way to make soil water content of around $40 \%$ field capacity. After one month of seedling transplantation, saline stresses were provided and the stress was increased gradually to prevent shock. Saline solution was continuously applied until the target salinity level reached. Plants were grown for four months in greenhouse (at $25-35{ }^{\circ} \mathrm{C}$, relative humidity: $65-70 \%$, photon flux intensity: $300-350 \mu \mathrm{mol} / \mathrm{m}^{2} / \mathrm{S}$ ).

\section{Plant dry weight}

After two months of seedling transplantation, plants from each treatment were harvested and washed in distilled deionized water. Fresh plants were kept in oven at $60{ }^{\circ} \mathrm{C}$ for $24 \mathrm{~h}$ for drying and then dry weights were recorded.

\section{Total chlorophyll content}

The youngest fully expanded fresh leaves from each treatment were collected for estimation of total chlorophyll content following the method of Strain and Svec (1966). Fresh leaf samples were first extracted in $80 \%(\mathrm{v} / \mathrm{v})$ acetone and then subjected to centrifugation. Concentrations of chlorophyll $a$ and chlorophyll $b$ of the supernatant were estimated by using spectrophotometer. Total chlorophyll content was determined and the value was expressed in terms of $\mathrm{mg} / \mathrm{g}$ leaf samples.

\section{Soluble protein content}

Fresh plant material (both shoot and root tissues) from each treatment was used for determination of soluble protein content. Sample was extracted in phosphate-buffered saline and then soluble protein content was detected by dye binding assay using 
Coomassie Brilliant Blue G 250 (Bradford, 1976). BSA was used as standard for the preparation of calibration curve.

\section{Soluble carbohydrate content}

Fresh plant material (both shoot and root tissues) from each treatment was subjected to acid hydrolysis and then total soluble carbohydrate content was estimated using anthrone method (Hedge and Hofreiter, 1962). Glucose was used as a standard for preparing the calibration curve.

\section{Reducing sugar content}

Fresh plant material (both shoot and root tissues) from individual treatment was extracted in hot ethanol for two successive times and total reducing sugar content was determined using 3,5-dinitrosalicylic acid method (Miller, 1972). Standard glucose solution was used for preparation of calibration curve.

\section{Free proline content}

Free proline content was determined by using Ninhydrin acid reagent (Bates et al., 1973). Fresh plant material (both shoot and root tissues) from each treatment was extracted in sulfo-salicylic acid (3\% w/v) and filtered through Whatman No. 2 filter paper. Filtrate was then treated with glacial acetic acid and acid ninhydrin reagent and was kept for boiling $(1 \mathrm{~h})$. After boiling, toluene was added to the reaction mixture and vortexed. Toluene layer was separated and absorbance of sample was measured at $520 \mathrm{~nm}$ using UV/Vis spectrophotometer (Shimadzu UV 1601). Standard proline was used for preparation of calibration curve.

\section{Electrolyte leakage (EL)}

Fresh leaf tissue from each treatment was used for determination of electrolyte leakage. Leaf samples were cut into small pieces of almost equal length and used for EL measurement. $0.5 \mathrm{~g}$ sample was taken in a test tube containing distilled deionized water and then placed in water bath (at $32{ }^{\circ} \mathrm{C}$ ) for $2 \mathrm{~h}$. After incubation, tubes were cooled to $25^{\circ} \mathrm{C}$ and initial electrical conductivity (EC) was measured using conductivity meter (Hanna, HI 8733). Then, the samples were autoclaved for $20 \mathrm{~min}$ and final EC was measured using conductivity meter (Hanna, HI 8733) after cooling the tubes at $25^{\circ} \mathrm{C}$ (Dionisio-Sese and Tobita, 1998). EL of fresh leaf samples was calculated using the following formula:

\section{$\mathrm{EL}=($ Initial EC/ Final EC $) \times 100$}

where $\mathrm{EL}=$ Electrolyte leakage; $\mathrm{EC}=$ Electrical conductivity.

\section{AM root colonization (\%)}

Root samples were washed with deionized water, followed by cutting it into $1 \mathrm{~cm}$ pieces. The root pieces were thoroughly mixed and a sub-sample $(0.5 \mathrm{~g})$ was cleared in hot $\mathrm{KOH}$ solution $\left(10 \% \mathrm{w} / \mathrm{v}\right.$, at $\left.90^{\circ} \mathrm{C}\right)$ for $1 \mathrm{~h}$. Cooled root samples were washed with deionized water and placed in $\mathrm{HCl}(10 \% \mathrm{v} / \mathrm{v})$ for $3 \mathrm{~min}$ and stained with trypan blue $(0.05 \% \mathrm{w} / \mathrm{v})$ for $15 \mathrm{~min}$ at $90{ }^{\circ} \mathrm{C}$ (Phillips and Hayman, 1970). Percentage of AM colonization in 384 mples was estimated by gridline intersects method (Giovannetti and Mosse, 1980).

\section{Statistical analysis}

Data were analyzed by ANOVA followed by Duncan's test and values of each treatment followed by different letters indicate statistically significant difference at $P<0.05$ level. SPSS v. 9.0 was used for the statistical data analysis.

\section{Results}

In the present study, soil salinity hampered growth and biochemical status of both the test plants regardless of mycorrhizal treatment. However, it was observed that, mycorrhizal colonization in G. max and C. tetragonoloba, reduced the extent of deleterious salt effect and improved plant growth even under provided soil salinity. Although, both the mycorrhizal isolates showed positive response in enhancement of host plant growth, but combined inoculation of both the isolates was found superior in this respect, followed by individual inoculation with $G m$ and $G f$.

\section{Plant dry weight}

G. max and C. tetragonoloba plants grown under control treatment $(1.04 \mathrm{dS} / \mathrm{m})$ had relatively more dry weight content than the corresponding plants from saline stress treatment $(2.10$ to $8.26 \mathrm{dS} / \mathrm{m})$. The values were significantly declined as soil salinity was increased from 2.10 to $8.26 \mathrm{dS} / \mathrm{m}$ regardless of mycorrhizal inoculations (Tab. 1).

With increasing soil salinity gradient dry weights of test plants were reduced, but under control $(1.04 \mathrm{dS} / \mathrm{m})$ and at each level of soil salinity (2.10 to $8.26 \mathrm{dS} / \mathrm{m}$ ) mycorrhizae inoculated plants had significantly higher dry weight than respective non-mycorrhizal plants. Moreover, inoculation with mixed mycorrhizal fungi was found to be superior over the individual inoculations. Individual effect of soil salinity and mycorrhizal fungi on dry weight was found significant for both the plants. However, their interaction was mainly significant with respect to dry weight content of G. $\max$ (Tab. 1).

\section{Total chlorophyll content}

Regardless of mycorrhizal inoculations, the test plants grown under control treatment $(1.04 \mathrm{dS} / \mathrm{m})$ had significantly higher chlorophyll content and the concentration was reduced with increase in salinity stress (Tab. 2).

However, at each level of soil salinity (2.10 to 8.26 $\mathrm{dS} / \mathrm{m})$ and in control treatment $(1.04 \mathrm{dS} / \mathrm{m})$, mycorrhizal colonization (individual and combined) in test plants resulted in significantly higher chlorophyll content as compared to respective non-mycorrhizal control plants (Tab. 2).

It was also observed that, regardless of salinity treatments, among the three types of mycorrhizal inoculations, combined mycorrhizae inoculated plants (G. max and C. tetragonoloba) showed higher chlorophyll content, than the corresponding plants inoculated with individual isolates (Tab. 2).

Soil salinity and mycorrhizal inoculations had significant effect on total chlorophyll content in G. max and $C$. tetragonoloba plants, and their interaction was 
384

Tab. 1. Dry weight (g/plant) of mycorrhizal and non-mycorrhizal G. max and C. tetragonoloba grown under control $(1.04 \mathrm{dS} / \mathrm{m})$ and at increasing soil salinity levels ( 2.10 to $8.26 \mathrm{dS} / \mathrm{m})$

\begin{tabular}{|c|c|c|c|}
\hline \multirow[t]{2}{*}{$\begin{array}{l}\text { Soil salinity } \\
(\mathrm{d} S / \mathrm{m})\end{array}$} & \multirow[t]{2}{*}{$\begin{array}{c}\mathrm{AM} \\
\text { inoculation }\end{array}$} & \multicolumn{2}{|c|}{$\begin{array}{l}\text { Chlorophyll content } \\
(\mathrm{mg} / \mathrm{g})\end{array}$} \\
\hline & & G. $\max$ & C. tetragonoloba \\
\hline \multirow{4}{*}{1.04} & NM & $1.757 \pm 0.03^{\mathrm{d}}$ & $1.571 \pm 0.03^{c}$ \\
\hline & $G m$ & $1.836 \pm 0.02^{\mathrm{b}}$ & $1.633 \pm 0.03^{b}$ \\
\hline & Gf & $1.781 \pm 0.01^{\mathrm{c}}$ & $1.598 \pm 0.03^{c}$ \\
\hline & $G m+G f$ & $1.871 \pm 0.02^{\mathrm{a}}$ & $1.663 \pm 0.02^{\mathrm{a}}$ \\
\hline \multirow{4}{*}{2.10} & NM & $1.588 \pm 0.03^{\mathrm{hi}}$ & $1.45 \pm 0.03^{f}$ \\
\hline & $G m$ & $1.673 \pm 0.02^{f}$ & $1.54 \pm 0.03^{\mathrm{d}}$ \\
\hline & $G f$ & $1.627 \pm 0.02^{\mathrm{g}}$ & $1.492 \pm 0.03^{\mathrm{e}}$ \\
\hline & $G m+G f$ & $1.722 \pm 0.02^{\mathrm{e}}$ & $1.573 \pm 0.03^{c}$ \\
\hline \multirow{4}{*}{3.78} & NM & $1.439 \pm 0.02^{\mathrm{k}}$ & $1.238 \pm 0.03^{\mathrm{i}}$ \\
\hline & $G m$ & $1.57 \pm 0.02^{\mathrm{i}}$ & $1.346 \pm 0.02^{g}$ \\
\hline & $G f$ & $1.517 \pm 0.02^{j}$ & $1.301 \pm 0.03^{\mathrm{h}}$ \\
\hline & $G m+G f$ & $1.6 \pm 0.02^{\mathrm{h}}$ & $1.369 \pm 0.03^{\mathrm{g}}$ \\
\hline \multirow{4}{*}{5.94} & NM & $1.187 \pm 0.03^{\circ}$ & $1.107 \pm 0.04^{1}$ \\
\hline & $G m$ & $1.301 \pm 0.02^{\mathrm{m}}$ & $1.202 \pm 0.03^{j}$ \\
\hline & Gf & $1.251 \pm 0.02^{\mathrm{n}}$ & $1.168 \pm 0.04^{k}$ \\
\hline & $G m+G f$ & $1.34 \pm 0.02^{1}$ & $1.229 \pm 0.04^{i j}$ \\
\hline \multirow{4}{*}{8.26} & NM & $0.978 \pm 0.02^{\mathrm{s}}$ & $0.931 \pm 0.05^{\circ}$ \\
\hline & $G m$ & $1.049 \pm 0.01^{\mathrm{q}}$ & $0.997 \pm 0.03^{\mathrm{mn}}$ \\
\hline & Gf & $1.02 \pm 0.02^{\mathrm{r}}$ & $0.971 \pm 0.03^{\mathrm{n}}$ \\
\hline & $G m+G f$ & $1.092 \pm 0.02^{\mathrm{p}}$ & $1.022 \pm 0.04^{\mathrm{m}}$ \\
\hline Salinity & & 0.000 & 0.000 \\
\hline Mycorrhizae & & 0.000 & 0.000 \\
\hline Salinity $\times$ Mycorrhizae & & 0.000 & 0.453 \\
\hline
\end{tabular}

NM: non mycorrhizal, Gm: Glomus mosseae, Gf: Glomus fasciculatum, Gm+Gf: Glomus mosseae + Glomus fasciculatum, values are mean \pm SE of three replicates. Within column, different letters for each treatment indicate statistically significant difference $(P<0.05)$ by Duncan's test after performing ANOVA

Tab. 2. Total chlorophyll content (mg/g) of mycorrhizal and non-mycorrhizal G. max and C. tetragonoloba grown under control (1.04dS/m) and at increasing soil salinity levels ( 2.10 to $8.26 \mathrm{dS} / \mathrm{m}$ )

\begin{tabular}{|c|c|c|c|}
\hline \multirow[t]{2}{*}{$\begin{array}{c}\text { Soil salinity } \\
(\mathrm{d} S / \mathrm{m})\end{array}$} & \multirow[t]{2}{*}{$\begin{array}{c}\text { A } \\
\text { inoculation }\end{array}$} & \multicolumn{2}{|c|}{$\begin{array}{l}\text { Chlorophyll content } \\
(\mathrm{mg} / \mathrm{g})\end{array}$} \\
\hline & & G. $\max$ & C. tetragonoloba \\
\hline \multirow{4}{*}{1.04} & NM & $1.668 \pm 0.01^{\mathrm{c}}$ & $1.401 \pm 0.02^{\mathrm{e}}$ \\
\hline & $G m$ & $1.779 \pm 0.01^{\mathrm{b}}$ & $1.507 \pm 0.01^{\mathrm{b}}$ \\
\hline & $G f$ & $1.737 \pm 0.01^{\mathrm{b}}$ & $1.485 \pm 0.01^{\mathrm{c}}$ \\
\hline & $G m+G f$ & $1.824 \pm 0.01^{\mathrm{a}}$ & $1.574 \pm 0.03^{\mathrm{a}}$ \\
\hline \multirow{4}{*}{2.10} & NM & $1.246 \pm 0.01^{\mathrm{f}}$ & $1.268 \pm 0.01^{\mathrm{g}}$ \\
\hline & $G m$ & $1.333 \pm 0.01^{\mathrm{de}}$ & $1.369 \pm 0.01^{\mathrm{f}}$ \\
\hline & $G f$ & $1.309 \pm 0.01^{\mathrm{e}}$ & $1.369 \pm 0.02^{f}$ \\
\hline & $G m+G f$ & $1.373 \pm 0.01^{\mathrm{d}}$ & $1.436 \pm 0.02^{\mathrm{d}}$ \\
\hline \multirow{4}{*}{3.78} & NM & $1.03 \pm 0.01^{\mathrm{i}}$ & $1.095 \pm 0.02^{\mathrm{i}}$ \\
\hline & Gm & $1.104 \pm 0.01^{\text {gh }}$ & $1.216 \pm 0.01^{\mathrm{h}}$ \\
\hline & $G f$ & $1.084 \pm 0.01^{\mathrm{h}}$ & $1.203 \pm 0.01^{\mathrm{h}}$ \\
\hline & $G m+G f$ & $1.153 \pm 0.01^{\mathrm{g}}$ & $1.257 \pm 0.01^{\mathrm{g}}$ \\
\hline \multirow{4}{*}{5.94} & NM & $0.827 \pm 0.01^{1}$ & $0.859 \pm 0.01^{\mathrm{m}}$ \\
\hline & $G m$ & $0.894 \pm 0.01^{\mathrm{jk}}$ & $0.954 \pm 0.01^{\mathrm{k}}$ \\
\hline & Gf & $0.869 \pm 0.01^{k}$ & $0.935 \pm 0.02^{1}$ \\
\hline & $G m+G f$ & $0.926 \pm 0.01^{i j}$ & $0.98 \pm 0.02^{j}$ \\
\hline \multirow{4}{*}{8.26} & NM & $0.537 \pm 0.01^{\circ}$ & $0.715 \pm 0.01^{q}$ \\
\hline & $G m$ & $0.573 \pm 0.01^{\mathrm{mn}}$ & $0.794 \pm 0.01^{\circ}$ \\
\hline & $G f$ & $0.548 \pm 0.01^{\mathrm{n}}$ & $0.774 \pm 0.02^{\mathrm{P}}$ \\
\hline & $G m+G f$ & $0.598 \pm 0.01^{\mathrm{m}}$ & $0.811 \pm 0.01^{\mathrm{n}}$ \\
\hline Salinity & & 0.000 & 0.000 \\
\hline Mycorrhizae & & 0.000 & 0.000 \\
\hline Salinity $\times$ Mycorrhizae & & 0.000 & 0.000 \\
\hline
\end{tabular}

NM: non mycorrhizal, Gm: Glomus mosseae, Gf: Glomus fasciculatum, Gm+Gf: Glomus mosseae + Glomus fasciculatum, values are mean \pm SE of three replicates. Within column, different letters for each treatment indicate statistically significant difference $(P<0.05)$ by Duncan's test after performing ANOVA 
also significant on total chlorophyll content of both the plants (Tab. 2).

\section{Soluble protein content}

Regardless of mycorrhizal inoculations, as compared to control $(1.04 \mathrm{dS} / \mathrm{m})$, salt stress (at salinity level of 2.10 $\mathrm{dS} / \mathrm{m}$ ) resulted in significant enhancement of soluble protein content of both the test plants, but with further increment in salinity stress level from 3.78 to $8.26 \mathrm{dS} / \mathrm{m}$, a significant reduction was noticed (Tab. 3).

Although, higher levels of soil salinity had negative impact on plant protein content, test plants inoculated with $G m$ and $G f$ isolates (individual and in combination) showed a significantly higher protein content as compared to non-mycorrhizal plants grown under control $(1.04 \mathrm{dS} / \mathrm{m})$ and at each level of soil salinity $(2.10$ to $8.26 \mathrm{dS} / \mathrm{m}$ ). Individual and combined effect of salinity and mycorrhizal inoculations were found significant on soluble protein contents of the test plants (Tab. 3).

\section{Soluble carbohydrate content}

In C. tetragonoloba plant, a steady, significant increment in soluble carbohydrate content was noticed, when the soil salinity was raised from control (1.04
$\mathrm{dS} / \mathrm{m}$ ) to $3.78 \mathrm{dS} / \mathrm{m}$ and with further increase in saline stress; the magnitude of carbohydrate content got reduced significantly irrespective of mycorrhizal inoculations. However, in G. max plant, the concentration of soluble carbohydrate significantly increased up to salinity stress level of $5.94 \mathrm{dS} / \mathrm{m}$, followed by a decreasing trend regardless of mycorrhizal inoculations (Tab. 4).

With increasing soil salinity either up to third or fourth level (3.78 or $5.94 \mathrm{dS} / \mathrm{m}$ ), soluble carbohydrate content increased steadily in mycorrhizae treated and untreated test plants; although comparatively higher concentration was found in plants following mycorrhizal inoculations $(G m$ and $G f)$. Combined inoculation of both the mycorrhizal isolates worked better in this regard. The individual and interactive effect of soil salinity and mycorrhizal inoculations were found significant on carbohydrate content of test plants (Tab. 4).

\section{Reducing sugar content}

During this study it was found that, regardless of mycorrhizal inoculations, reducing sugar content of $G$. max and C. tetragonoloba plants increased significantly

Tab. 3. Total soluble protein content (mg/g) of mycorrhizal and non-mycorrhizal G. max and C. tetragonoloba grown under control (1.04 dS/m) and at increasing soil salinity levels $(2.10$ to $8.26 \mathrm{dS} / \mathrm{m})$

\begin{tabular}{|c|c|c|c|}
\hline $\begin{array}{l}\text { Soil salinity } \\
(\mathrm{dS} / \mathrm{m})\end{array}$ & $\begin{array}{c}\mathrm{AM} \\
\text { inoculation } \\
\end{array}$ & $\begin{array}{c}\text { Chlorophyll content } \\
(\mathrm{mg} / \mathrm{g})\end{array}$ & $\begin{array}{c}\text { Soil salinity } \\
(\mathrm{dS} / \mathrm{m})\end{array}$ \\
\hline & & G. $\max$ & C. tetragonoloba \\
\hline \multirow{4}{*}{1.04} & NM & $10.892 \pm 0.36^{\mathrm{m}}$ & $9.32 \pm 0.32^{\mathrm{g}}$ \\
\hline & $G m$ & $11.398 \pm 0.46^{j}$ & $9.742 \pm 0.35^{\mathrm{e}}$ \\
\hline & $G f$ & $11.228 \pm 0.51^{\mathrm{k}}$ & $9.591 \pm 0.26^{\mathrm{ef}}$ \\
\hline & $G m+G f$ & $11.831 \pm 0.35^{\mathrm{i}}$ & $10.086 \pm 0.22^{\mathrm{d}}$ \\
\hline \multirow{4}{*}{2.10} & NM & $14.146 \pm 0.44^{\mathrm{f}}$ & $11.919 \pm 0.94^{c}$ \\
\hline & $G m$ & $14.926 \pm 0.44^{c}$ & $12.527 \pm 0.21^{\mathrm{b}}$ \\
\hline & $G f$ & $14.654 \pm 0.42^{\mathrm{d}}$ & $12.313 \pm 0.25^{\mathrm{b}}$ \\
\hline & $G m+G f$ & $15.727 \pm 0.48^{\mathrm{a}}$ & $13.254 \pm 0.25^{\mathrm{a}}$ \\
\hline \multirow{4}{*}{3.78} & NM & $13.334 \pm 0.57^{\mathrm{h}}$ & $9.055 \pm 0.29^{h}$ \\
\hline & $G m$ & $14.554 \pm 0.49^{\mathrm{e}}$ & $9.792 \pm 0.25^{\mathrm{e}}$ \\
\hline & $G f$ & $13.969 \pm 0.6^{\mathrm{g}}$ & $9.432 \pm 0.26^{\mathrm{fg}}$ \\
\hline & $G m+G f$ & $15.174 \pm 0.35^{b}$ & $10.308 \pm 0.2^{\mathrm{d}}$ \\
\hline \multirow{4}{*}{5.94} & NM & $9.382 \pm 0.87^{\mathrm{P}}$ & $4.974 \pm 0.34^{k}$ \\
\hline & $G m$ & $10.338 \pm 0.59^{\mathrm{n}}$ & $5.479 \pm 0.27^{j}$ \\
\hline & $G f$ & $9.877 \pm 0.55^{\circ}$ & $5.189 \pm 0.24^{k}$ \\
\hline & $G m+G f$ & $10.96 \pm 0.43^{1}$ & $5.723 \pm 0.39^{\mathrm{i}}$ \\
\hline \multirow{4}{*}{8.26} & NM & $6.327 \pm 0.68^{t}$ & $3.972 \pm 0.43^{\mathrm{m}}$ \\
\hline & $G m$ & $6.939 \pm 0.84^{\mathrm{r}}$ & $4.359 \pm 0.3^{1}$ \\
\hline & $G f$ & $6.583 \pm 0.56^{\mathrm{s}}$ & $4.084 \pm 0.28^{\mathrm{m}}$ \\
\hline & $G m+G f$ & $7.302 \pm 0.5^{q}$ & $4.537 \pm 0.35^{1}$ \\
\hline Salinity & & 0.000 & 0.000 \\
\hline Mycorrhizae & & 0.000 & 0.000 \\
\hline Salinity x Mycorrhizae & & 0.000 & 0.002 \\
\hline
\end{tabular}

NM: non mycorrhizal, Gm: Glomus mosseae, Gf: Glomus fasciculatum, Gm+Gf: Glomus mosseae + Glomus fasciculatum, values are mean \pm SE of three replicates. Within column, different letters for each treatment indicate statistically significant difference $(P<0.05)$ by Duncan's test after performing ANOVA 
Tab. 4. Total soluble carbohydrate content $(\mathrm{mg} / \mathrm{g})$ of mycorrhizal and non-mycorrhizal G. max and C. tetragonoloba grown under control (1.04 $\mathrm{dS} / \mathrm{m})$ and at increasing soil salinity levels $(2.10$ to $8.26 \mathrm{dS} / \mathrm{m})$

\begin{tabular}{|c|c|c|c|}
\hline $\begin{array}{l}\text { Soil salinity } \\
(\mathrm{d} S / \mathrm{m})\end{array}$ & $\begin{array}{c}\mathrm{AM} \\
\text { inoculation }\end{array}$ & $\begin{array}{c}\text { Chlorophyll content } \\
(\mathrm{mg} / \mathrm{g})\end{array}$ & $\begin{array}{l}\text { Soil salinity } \\
(\mathrm{d} S / \mathrm{m})\end{array}$ \\
\hline & & G. $\max$ & C. tetragonoloba \\
\hline \multirow{4}{*}{1.04} & NM & $13.733 \pm 0.28^{\mathrm{t}}$ & $15.876 \pm 0.5^{\mathrm{s}}$ \\
\hline & $G m$ & $14.586 \pm 0.32^{\mathrm{r}}$ & $16.804 \pm 0.35^{\mathrm{q}}$ \\
\hline & $G f$ & $14.105 \pm 0.4^{\mathrm{s}}$ & $16.293 \pm 0.48^{\mathrm{r}}$ \\
\hline & $G m+G f$ & $15.05 \pm 0.39^{9}$ & $17.297 \pm 0.56^{\mathrm{P}}$ \\
\hline \multirow{4}{*}{2.10} & NM & $15.64 \pm 0.33^{P}$ & $17.878 \pm 0.51^{\circ}$ \\
\hline & $G m$ & $16.865 \pm 0.37^{\mathrm{m}}$ & $19.406 \pm 0.25^{1}$ \\
\hline & Gf & $16.285 \pm 0.26^{\circ}$ & $18.662 \pm 0.39^{\mathrm{m}}$ \\
\hline & $G m+G f$ & $17.435 \pm 0.28^{1}$ & $19.766 \pm 0.5^{\mathrm{k}}$ \\
\hline \multirow{4}{*}{3.78} & $\mathrm{NM}$ & $16.693 \pm 0.32^{\mathrm{n}}$ & $21.516 \pm 0.88^{\mathrm{h}}$ \\
\hline & $G m$ & $18.612 \pm 0.42^{\mathrm{i}}$ & $24.105 \pm 0.47^{\mathrm{c}}$ \\
\hline & Gf & $17.564 \pm 0.23^{k}$ & $22.977 \pm 0.44^{\mathrm{e}}$ \\
\hline & $G m+G f$ & $18.981 \pm 0.43^{\mathrm{h}}$ & $24.552 \pm 0.54^{\mathrm{a}}$ \\
\hline \multirow{4}{*}{5.94} & NM & $19.445 \pm 0.3^{\mathrm{f}}$ & $20.653 \pm 0.66^{j}$ \\
\hline & $G m$ & $21.914 \pm 0.38^{b}$ & $23.601 \pm 0.52^{\mathrm{d}}$ \\
\hline & Gf & $20.531 \pm 0.51^{\mathrm{d}}$ & $21.979 \pm 0.55^{\mathrm{f}}$ \\
\hline & $G m+G f$ & $23.107 \pm 0.28^{\mathrm{a}}$ & $24.217 \pm 0.37^{b}$ \\
\hline \multirow{4}{*}{8.26} & NM & $18.201 \pm 0.41^{j}$ & $18.429 \pm 0.34^{\mathrm{n}}$ \\
\hline & $G m$ & $20.431 \pm 0.33^{e}$ & $20.954 \pm 0.46^{\mathrm{i}}$ \\
\hline & Gf & $19.016 \pm 0.32^{\mathrm{g}}$ & $19.384 \pm 0.36^{1}$ \\
\hline & $G m+G f$ & $21.536 \pm 0.44^{c}$ & $21.582 \pm 0.4^{g}$ \\
\hline Salinity & & 0.000 & 0.000 \\
\hline Mycorrhizae & & 0.000 & 0.000 \\
\hline Salinity x Mycorrhizae & & 0.000 & 0.000 \\
\hline
\end{tabular}

NM: non mycorrhizal, Gm: Glomus mosseae, Gf: Glomus fasciculatum, Gm+Gf: Glomus mosseae + Glomus fasciculatum, values are mean \pm SE of three replicates. Within column, different letters for each treatment indicate statistically significant difference $(P<0.05)$ by Duncan's test after performing ANOVA

with increasing soil salinity stress from control (1.04 $\mathrm{dS} / \mathrm{m}$ ) to $3.78 \mathrm{dS} / \mathrm{m}$. However, with further increment in saline stress, a significant reduction was noted (Tab. 5).

Even though, due to saline stress gradient (up to 3.78 $\mathrm{d} S / \mathrm{m})$, reducing sugar content was increased in mycorrhizae inoculated and non-mycorrhizal test plants, but $G m$ and $G f$ colonized (with individual and combined) test plants had significantly higher amount of reducing sugar over corresponding non-mycorrhizal plants under control $(1.04 \mathrm{dS} / \mathrm{m})$ and provided salinity stress gradient $(2.10$ to $8.26 \mathrm{dS} / \mathrm{m})$ (Tab. 5).

Moreover, test plants colonized with both $G m$ and $G f$ isolates had reducing sugar contents to a little higher amount as compared to corresponding plants with individual $G m$ and $G f$ isolates. Individual effect of soil salinity and mycorrhizal colonization and their interaction were found significant on reducing sugar contents of test plants (Tab. 5).

\section{Free proline content}

Proline concentration in test plants was significantly improved under increasing soil salinity up to $5.94 \mathrm{dS} / \mathrm{m}$, regardless of mycorrhizal inoculations. Then it was reduced $(P<0.05)$ in mycorrhizal and non-mycorrhizal plants at the highest level of soil salinity $(8.26 \mathrm{dS} / \mathrm{m})$ (Tab. 6).

It is worth noting that, even though, increasing soil salinity gradient (up to $5.94 \mathrm{dS} / \mathrm{m}$ ) resulted in enhancement of proline concentration, but as compared to non-mycorrhizal plants, mycorrhizal plants had significantly higher proline content at control (1.04 $\mathrm{d} S / \mathrm{m})$ and soil salinity gradient $(2.10$ to $8.26 \mathrm{dS} / \mathrm{m})$ in case of both the plants. Plants with combined mycorrhizal treatment showed more proline content over the corresponding plants colonized with individual $G m$ and $G f$ isolates, when exposed to control (1.04 $\mathrm{dS} / \mathrm{m})$ and soil salinity stress gradient (2.10 to 8.26 $\mathrm{dS} / \mathrm{m})$ (Tab. 6).

Soil salinity and mycorrhizal inoculations when considered individually and in combination showed a significant effect on proline content of $G$. $\max$ and $C$. tetragonoloba plants (Tab. 6).

\section{Electrolyte Leakage}

Percent electrolyte leakage of mycorrhizae inoculated and non-mycorrhizal test plants grown under control $(1.04 \mathrm{dS} / \mathrm{m})$ and various levels of soil salinity is presented in Tab. 7.

Test plants subjected to control treatment (1.04 $\mathrm{dS} / \mathrm{m})$ had relatively less electrolyte leakage concentration (\%) and the values increased rapidly with increase in soil salinity stress $(2.10$ to $8.26 \mathrm{dS} / \mathrm{m})$, irrespective of mycorrhizal inoculations. Although salt stress increased electrolyte leakage in test plants, but mycorrhizal inoculation significantly lowered percent electrolyte leakage in all the plants grown at each level of soil salinity $(2.10$ to $8.26 \mathrm{dS} / \mathrm{m}$ ) (Tab. 7$)$. 
Tab. 5. Total reducing sugar content (mg/g) of mycorrhizal and non-mycorrhizal G. max and C. tetragonoloba grown under control (1.04 dS/m) and at increasing soil salinity levels $(2.10$ to $8.26 \mathrm{dS} / \mathrm{m})$

\begin{tabular}{|c|c|c|c|}
\hline $\begin{array}{l}\text { Soil salinity } \\
(\mathrm{d} S / \mathrm{m})\end{array}$ & $\begin{array}{c}\mathrm{AM} \\
\text { inoculation }\end{array}$ & $\begin{array}{c}\text { Chlorophyll content } \\
(\mathrm{mg} / \mathrm{g})\end{array}$ & $\begin{array}{l}\text { Soil salinity } \\
(\mathrm{d} S / \mathrm{m})\end{array}$ \\
\hline & & G. $\max$ & C. tetragonoloba \\
\hline \multirow{4}{*}{1.04} & NM & $7.624 \pm 0.3^{r}$ & $13.163 \pm 0.31^{1}$ \\
\hline & $G m$ & $7.854 \pm 0.4^{\circ}$ & $13.51 \pm 0.36^{j}$ \\
\hline & Gf & $7.727 \pm 0.21^{q}$ & $13.259 \pm 0.26^{k}$ \\
\hline & $G m+G f$ & $8.119 \pm 0.27^{\mathrm{n}}$ & $14 \pm 0.38^{\mathrm{i}}$ \\
\hline \multirow{4}{*}{2.10} & NM & $8.59 \pm 0.35^{1}$ & $14.37 \pm 0.36^{\mathrm{h}}$ \\
\hline & $G m$ & $9.078 \pm 0.29^{j}$ & $14.923 \pm 0.39^{f}$ \\
\hline & Gf & $8.774 \pm 0.27^{k}$ & $14.623 \pm 0.38^{g}$ \\
\hline & $G m+G f$ & $9.258 \pm 0.33^{\mathrm{i}}$ & $15.436 \pm 0.44^{\mathrm{e}}$ \\
\hline \multirow{4}{*}{3.78} & NM & $11.155 \pm 0.25^{f}$ & $15.746 \pm 0.36^{\mathrm{d}}$ \\
\hline & $G m$ & $11.916 \pm 0.29^{b}$ & $16.697 \pm 0.37^{b}$ \\
\hline & Gf & $11.539 \pm 0.3^{\mathrm{d}}$ & $16.106 \pm 0.5^{c}$ \\
\hline & $G m+G f$ & $12.469 \pm 0.3^{\mathrm{a}}$ & $17.351 \pm 0.28^{a}$ \\
\hline \multirow{4}{*}{5.94} & NM & $10.393 \pm 0.21^{\mathrm{h}}$ & $11.474 \pm 0.48^{\mathrm{P}}$ \\
\hline & $G m$ & $11.214 \pm 0.26^{\mathrm{e}}$ & $12.277 \pm 0.33^{\mathrm{n}}$ \\
\hline & Gf & $10.85 \pm 0.26^{\mathrm{g}}$ & $11.79 \pm 0.27^{\circ}$ \\
\hline & $G m+G f$ & $11.742 \pm 0.28^{c}$ & $12.673 \pm 0.26^{\mathrm{m}}$ \\
\hline \multirow{4}{*}{8.26} & NM & $7.415 \pm 0.25^{t}$ & $7.247 \pm 0.5^{t}$ \\
\hline & $G m$ & $7.757 \pm 0.26^{\mathrm{P}}$ & $7.473 \pm 0.39^{\mathrm{r}}$ \\
\hline & Gf & $7.517 \pm 0.26^{\mathrm{s}}$ & $7.353 \pm 0.32^{s}$ \\
\hline & $G m+G f$ & $8.144 \pm 0.16^{\mathrm{m}}$ & $7.831 \pm 0.37^{9}$ \\
\hline Salinity & & 0.000 & 0.000 \\
\hline Mycorrhizae & & 0.000 & 0.000 \\
\hline Salinity x Mycorrhizae & & 0.000 & 0.000 \\
\hline
\end{tabular}

NM: non mycorrhizal, Gm: Glomus mosseae, Gf: Glomus fasciculatum, Gm+Gf: Glomus mosseae + Glomus fasciculatum, values are mean \pm SE of three replicates. Within column, different letters for each treatment indicate statistically significant difference $(P<0.05)$ by Duncan's test after performing ANOVA

Tab. 6. Total proline content $(\mu \mathrm{mol} / \mathrm{g})$ of mycorrhizal and non-mycorrhizal G. max and C. tetragonoloba grown under control (1.04 dS/m) and at increasing soil salinity levels $(2.10$ to $8.26 \mathrm{dS} / \mathrm{m})$

\begin{tabular}{|c|c|c|c|}
\hline \multirow[t]{2}{*}{$\begin{array}{l}\text { Soil salinity } \\
(\mathrm{d} S / \mathrm{m})\end{array}$} & \multirow[t]{2}{*}{$\begin{array}{c}\mathrm{AM} \\
\text { inoculation } \\
\end{array}$} & \multicolumn{2}{|c|}{$\begin{array}{c}\text { Chlorophyll content } \\
(\mathrm{mg} / \mathrm{g})\end{array}$} \\
\hline & & G. $\max$ & C. tetragonoloba \\
\hline \multirow{4}{*}{1.04} & NM & $1.163 \pm 0.25^{\mathrm{t}}$ & $1.355 \pm 0.17^{\mathrm{t}}$ \\
\hline & $G m$ & $1.211 \pm 0.18^{\mathrm{r}}$ & $1.414 \pm 0.18^{\mathrm{r}}$ \\
\hline & Gf & $1.179 \pm 0.11^{\mathrm{s}}$ & $1.378 \pm 0.21^{\mathrm{s}}$ \\
\hline & $G m+G f$ & $1.232 \pm 0.11^{\mathrm{q}}$ & $1.443 \pm 0.21^{\mathrm{q}}$ \\
\hline \multirow{4}{*}{2.10} & NM & $1.328 \pm 0.14^{\mathrm{P}}$ & $1.55 \pm 0.21^{\mathrm{P}}$ \\
\hline & $G m$ & $1.391 \pm 0.12^{\mathrm{n}}$ & $1.633 \pm 0.24^{\mathrm{n}}$ \\
\hline & Gf & $1.354 \pm 0.15^{\circ}$ & $1.577 \pm 0.13^{\circ}$ \\
\hline & $G m+G f$ & $1.421 \pm 0.1^{\mathrm{m}}$ & $1.661 \pm 0.24^{\mathrm{m}}$ \\
\hline \multirow{4}{*}{3.78} & NM & $1.504 \pm 0.14^{1}$ & $1.752 \pm 0.22^{1}$ \\
\hline & $G m$ & $1.581 \pm 0.1^{\mathrm{j}}$ & $1.858 \pm 0.23^{j}$ \\
\hline & Gf & $1.556 \pm 0.11^{\mathrm{k}}$ & $1.804 \pm 0.18^{k}$ \\
\hline & $G m+G f$ & $1.618 \pm 0.09^{i}$ & $1.906 \pm 0.26^{\mathrm{i}}$ \\
\hline \multirow{4}{*}{5.94} & NM & $1.694 \pm 0.15^{\mathrm{g}}$ & $2.118 \pm 0.21^{\mathrm{g}}$ \\
\hline & $G m$ & $1.79 \pm 0.12^{\mathrm{b}}$ & $2.258 \pm 0.34^{\mathrm{b}}$ \\
\hline & $G f$ & $1.749 \pm 0.09^{\mathrm{d}}$ & $2.195 \pm 0.17^{\mathrm{d}}$ \\
\hline & $G m+G f$ & $1.849 \pm 0.11^{a}$ & $2.3 \pm 0.26^{\mathrm{a}}$ \\
\hline \multirow{4}{*}{8.26} & NM & $1.669 \pm 0.13^{\mathrm{h}}$ & $2.075 \pm 0.15^{\mathrm{h}}$ \\
\hline & $G m$ & $1.737 \pm 0.13^{\mathrm{e}}$ & $2.176 \pm 0.13^{\mathrm{e}}$ \\
\hline & $G f$ & $1.709 \pm 0.12^{\mathrm{f}}$ & $2.14 \pm 0.14^{\mathrm{f}}$ \\
\hline & $G m+G f$ & $1.779 \pm 0.1^{\mathrm{c}}$ & $2.217 \pm 0.13^{\mathrm{c}}$ \\
\hline Salinity & & 0.000 & 0.000 \\
\hline Mycorrhizae & & 0.000 & 0.000 \\
\hline Salinity $\times$ Mycorrhizae & & 0.000 & 0.000 \\
\hline
\end{tabular}

NM: non mycorrhizal, Gm: Glomus mosseae, Gf: Glomus fasciculatum, Gm+Gf: Glomus mosseae + Glomus fasciculatum, values are mean \pm SE of three replicates. Within column, different letters for each treatment indicate statistically significant difference $(P<0.05)$ by Duncan's test after performing ANOVA 
388

Even though, combined mycorrhizal inoculation with both $G m$ and $G f$ isolates reduced this to a greater magnitude. However, exact opposite trend was observed in control $(1.04 \mathrm{dS} / \mathrm{m})$ treatment, where mycorrhizae inoculated plants showed higher percentage of electrolyte leakage over non-mycorrhizal counterparts of both the test plants. Individual and combined effect of soil salinity and mycorrhizal inoculations were found significant with respect to percent electrolyte leakage of test plants (Tab. 7).

\section{Root colonization}

At the end of the whole study, non-mycorrhizal plants remained uncolonized whereas, AM colonization was detected in mycorrhizae inoculated test plants exposed to control $(1.04 \mathrm{dS} / \mathrm{m})$ and soil salinity gradient up to $8.26 \mathrm{dS} / \mathrm{m}$ (Tab. 8 ).

Due to individual and combined AM inoculations, the magnitude of root colonization was different and relatively higher AM root colonization was noticed in plants inoculated with combined isolates followed by individual colonization with $G m$ and $G f$ isolates under control $(1.04 \mathrm{dS} / \mathrm{m})$ and each soil salinity level (2.10 to $8.26 \mathrm{dS} / \mathrm{m})$ (Tab. 8).

Soil salinity and mycorrhizal inoculation when considered individually a significant effect on AM root colonization was observed in case of both the test plants. However, their interaction was mainly non-significant on this parameter (Tab. 8).

\section{Mycorrhizal response on plant dry weight and various biochemical parameters}

The overall effect of AM inoculations with $G m$ and $G f$ isolates (individually and in combination) on test plant dry weight and accumulation of various biochemical constituents was determined over respective non-mycorrhizal plants grown under control $(1.04$ $\mathrm{dS} / \mathrm{m})$ and each level of soil salinity $(2.10$ to $8.26 \mathrm{dS} / \mathrm{m})$ (Fig. 1a to $1 \mathrm{f}$ ).

Tab. 7. Percent electrolyte leakage of mycorrhizal and non-mycorrhizal G. max and C. tetragonoloba grown under control $(1.04 \mathrm{dS} / \mathrm{m})$ and at increasing soil salinity levels $(2.10$ to $8.26 \mathrm{dS} / \mathrm{m})$

\begin{tabular}{|c|c|c|c|}
\hline \multirow[t]{2}{*}{$\begin{array}{l}\text { Soil salinity } \\
\text { (dS/m) }\end{array}$} & \multirow[t]{2}{*}{$\begin{array}{c}\mathrm{AM} \\
\text { inoculation }\end{array}$} & \multicolumn{2}{|c|}{$\begin{array}{l}\text { Chlorophyll content } \\
(\mathrm{mg} / \mathrm{g})\end{array}$} \\
\hline & & G. $\max$ & C. tetragonoloba \\
\hline \multirow{4}{*}{1.04} & NM & $8.59 \pm 0.26^{\circ}$ & $8.68 \pm 0.17^{9}$ \\
\hline & $G m$ & $9.06 \pm 0.04^{\mathrm{n}}$ & $9.03 \pm 0.26^{\circ}$ \\
\hline & $G f$ & $8.72 \pm 0.21^{\circ}$ & $8.73 \pm 0.16^{\mathrm{P}}$ \\
\hline & $G m+G f$ & $9.73 \pm 0.15^{\mathrm{m}}$ & $9.79 \pm 0.1^{\mathrm{n}}$ \\
\hline \multirow{4}{*}{2.10} & NM & $11.16 \pm 0.15^{\mathrm{k}}$ & $15.78 \pm 0.34^{j}$ \\
\hline & $G m$ & $9.68 \pm 0.12^{\mathrm{m}}$ & $11.95 \pm 0.18^{1}$ \\
\hline & Gf & $10.44 \pm 0.36^{1}$ & $13.32 \pm 0.17^{\mathrm{k}}$ \\
\hline & $G m+G f$ & $9.53 \pm 0.27^{\mathrm{m}}$ & $11.6 \pm 0.25^{\mathrm{m}}$ \\
\hline \multirow{4}{*}{3.78} & $\mathrm{NM}$ & $19.4 \pm 0.31^{\mathrm{h}}$ & $24.06 \pm 0.28^{\mathrm{d}}$ \\
\hline & $G m$ & $16.91 \pm 0.16^{j}$ & $17.89 \pm 0.2^{\mathrm{i}}$ \\
\hline & $G f$ & $18.71 \pm 0.24^{\mathrm{i}}$ & $20.88 \pm 0.25^{\mathrm{g}}$ \\
\hline & $G m+G f$ & $16.77 \pm 0.17^{j}$ & $17.72 \pm 0.31^{\mathrm{i}}$ \\
\hline \multirow{4}{*}{5.94} & NM & $27.55 \pm 0.14^{\mathrm{b}}$ & $30.25 \pm 0.11^{\mathrm{b}}$ \\
\hline & Gm & $20.92 \pm 0.09^{\mathrm{e}}$ & $21.12 \pm 0.15^{\mathrm{g}}$ \\
\hline & $G f$ & $22.11 \pm 0.1^{\mathrm{d}}$ & $22.36 \pm 0.28^{\mathrm{e}}$ \\
\hline & $G m+G f$ & $20.43 \pm 0.24^{\mathrm{g}}$ & $20.34 \pm 0.21^{\mathrm{h}}$ \\
\hline \multirow{4}{*}{8.26} & NM & $32.93 \pm 0.19^{\mathrm{a}}$ & $36.4 \pm 0.26^{a}$ \\
\hline & $G m$ & $21.13 \pm 0.15^{\mathrm{e}}$ & $21.73 \pm 0.2^{\mathrm{f}}$ \\
\hline & Gf & $26.35 \pm 0.21^{c}$ & $27.97 \pm 0.23^{c}$ \\
\hline & $G m+G f$ & $20.82 \pm 0.4^{\mathrm{f}}$ & $21.05 \pm 0.19^{g}$ \\
\hline $\begin{array}{l}\text { Salinity } \\
\text { Mycorrhizae } \\
\text { Salinity } \times \text { Mycorrhizae }\end{array}$ & & $\begin{array}{l}0.000 \\
0.000 \\
0.000\end{array}$ & $\begin{array}{l}0.000 \\
0.000 \\
0.000\end{array}$ \\
\hline
\end{tabular}

NM: non mycorrhizal, Gm: Glomus mosseae, Gf: Glomus fasciculatum, Gm+Gf: Glomus mosseae + Glomus fasciculatum, values are mean \pm SE of three replicates. Within column, different letters for each treatment indicate statistically significant difference $(P<0.05)$ by Duncan's test after performing ANOVA

In $G$. max and $C$. tetragonoloba plants, $\mathrm{AM}$ constituents (protein and reducing sugar) and dry weight inoculations ( $G m$ and $G f)$ increased dry weight yield, yield (Fig. 1a to 1f). chlorophyll, protein, proline, carbohydrate and reducing sugar content to a maximum amount at soil salinity either of $3.78 \mathrm{dS} / \mathrm{m}$ or of $5.94 \mathrm{dS} / \mathrm{m}$.

At control $(1.04 \mathrm{dS} / \mathrm{m})$ and various soil salinity levels $(2.10$ to $8.26 \mathrm{dS} / \mathrm{m})$, the effect of individual and combine mycorrhizal inoculations (with $G m$ and $G f$ isolates) was more pronounced in G. max over C. tetragonoloba, in response to higher accumulation of several biochemical
However, better accumulation of total chlorophyll, proline and carbohydrate content was noticed in $C$. tetragonoloba as compared to $G$. max, following individual and combined inoculation with AM isolates under various levels of soil salinity. Moreover, it was observed that, regardless of test plants and soil salinity, the acquisition of biochemical constituents was found to be higher following combined inoculation with $G m$ and 
Tab. 8. Percent root colonization of mycorrhizal and non-mycorrhizal G. max and C. tetragonoloba grown under control (1.04 dS/m) and at increasing soil salinity levels $(2.10$ to $8.26 \mathrm{dS} / \mathrm{m})$

\begin{tabular}{|c|c|c|c|}
\hline \multirow[t]{2}{*}{$\begin{array}{l}\text { Soil salinity } \\
(\mathrm{d} S / \mathrm{m})\end{array}$} & \multirow[t]{2}{*}{$\begin{array}{c}\mathrm{AM} \\
\text { inoculation }\end{array}$} & \multicolumn{2}{|c|}{$\begin{array}{l}\text { Chlorophyll content } \\
(\mathrm{mg} / \mathrm{g})\end{array}$} \\
\hline & & G. $\max$ & C. tetragonoloba \\
\hline \multirow{4}{*}{1.04} & NM & $0^{\mathrm{f}}$ & $0^{\mathrm{f}}$ \\
\hline & $G m$ & $18.17 \pm 6.79^{\mathrm{bcd}}$ & $28.5 \pm 8.38^{\mathrm{abc}}$ \\
\hline & $G f$ & $15 \pm 6.26^{\text {cde }}$ & $27.83 \pm 9.47^{\mathrm{abcd}}$ \\
\hline & $G m+G f$ & $26.33 \pm 8.5^{a}$ & $35 \pm 7.82^{\mathrm{a}}$ \\
\hline \multirow{4}{*}{2.10} & NM & $0^{\mathrm{f}}$ & $0^{\mathrm{f}}$ \\
\hline & Gm & $16.67 \pm 7.31^{\mathrm{cde}}$ & $27.67 \pm 5.75^{\text {abcd }}$ \\
\hline & $G f$ & $13.33 \pm 5.13^{\mathrm{de}}$ & $27.5 \pm 13.4^{\mathrm{abcd}}$ \\
\hline & $G m+G f$ & $24.67 \pm 7.23^{\mathrm{ab}}$ & $32.67 \pm 9.93^{\mathrm{ab}}$ \\
\hline \multirow{4}{*}{3.78} & NM & $0^{f}$ & $0^{f}$ \\
\hline & $G m$ & $14.83 \pm 6.18^{\text {cde }}$ & $26.5 \pm 12.44^{\text {abcde }}$ \\
\hline & $G f$ & $12.17 \pm 5.78^{\mathrm{de}}$ & $24.17 \pm 6.97^{\text {bdde }}$ \\
\hline & $G m+G f$ & $22 \pm 5.29^{\mathrm{abc}}$ & $29.5 \pm 9.91^{\mathrm{abc}}$ \\
\hline \multirow{4}{*}{5.94} & NM & $0^{\mathrm{f}}$ & $0^{\mathrm{f}}$ \\
\hline & $G m$ & $15.5 \pm 6.66^{\text {cde }}$ & $19.33 \pm 6.8^{\text {cde }}$ \\
\hline & Gf & $12 \pm 5.69^{\mathrm{de}}$ & $18 \pm 8.74^{\mathrm{de}}$ \\
\hline & $G m+G f$ & $19.33 \pm 6.71^{\mathrm{abcd}}$ & $24 \pm 7.51^{\text {bcde }}$ \\
\hline \multirow{4}{*}{8.26} & NM & $0^{\mathrm{f}}$ & $0^{\mathrm{f}}$ \\
\hline & $G m$ & $12.35 \pm 5.24^{\mathrm{de}}$ & $17.33 \pm 5.54^{e}$ \\
\hline & Gf & $9.5 \pm 3.89^{\mathrm{e}}$ & $17.17 \pm 6.94^{e}$ \\
\hline & $G m+G f$ & $16.33 \pm 9.05^{\mathrm{cde}}$ & $22.5 \pm 6.89^{\mathrm{bcde}}$ \\
\hline Salinity & & 0.019 & 0.000 \\
\hline Mycorrhizae & & 0.000 & 0.000 \\
\hline Salinity $\times$ Mycorrhizae & & 0.883 & 0.705 \\
\hline
\end{tabular}

NM: non mycorrhizal, Gm: Glomus mosseae, Gf: Glomus fasciculatum, Gm+Gf: Glomus mosseae + Glomus fasciculatum, values are mean \pm SE of three replicates. Within column, different letters for each treatment indicate statistically significant difference $(P<0.05)$ by Duncan's test after performing ANOVA

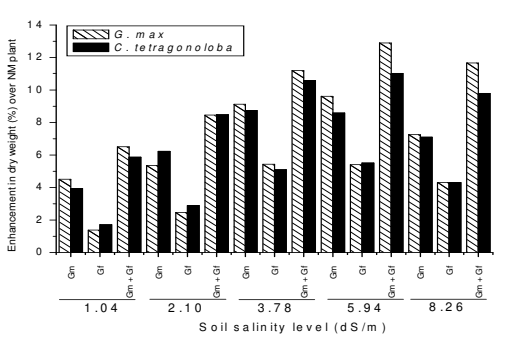

a.

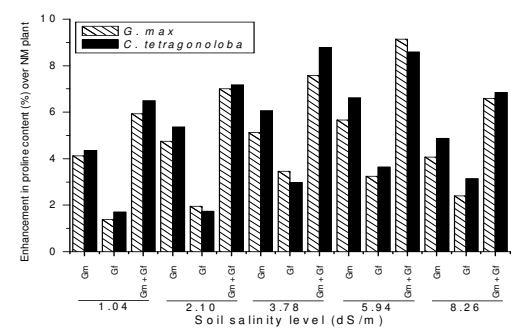

d.

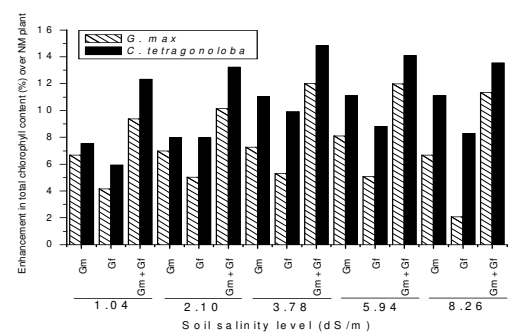

b.

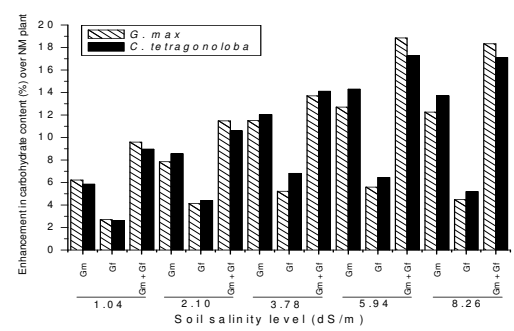

e.

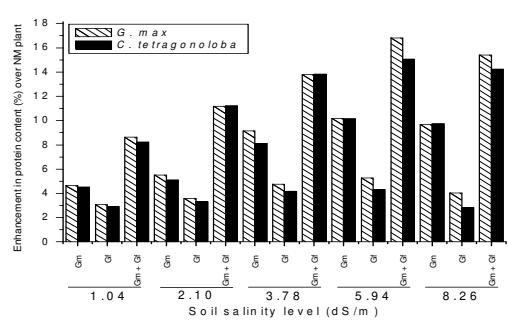

c.

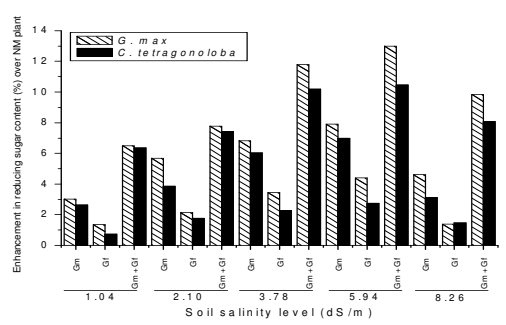

f.

Fig. 1. Mycorrhizal response on enhancement of (a) dry weight yield, (b) total chlorophyll, (c) soluble protein, (d) free proline, (e) soluble carbohydrate, (f) reducing sugar content in individual and combined AM inoculated G. max and C. tetragonoloba over corresponding non-mycorrhizal plants exposed to control $(1.04 \mathrm{dS} / \mathrm{m})$ and increasing soil salinity gradient $(2.10$ to 8.26 $\mathrm{d} S / \mathrm{m})$ 
390

$G f$ than their individual colonization.

\section{Discussion}

This study investigated the effect of two indigenous $\mathrm{AM}$ isolates in promoting growth in terms of dry weight matter and various biochemical parameters at different levels of salt stress.

Dry weight of mycorrhizae treated and untreated $G$. $\max$ and $C$. tetragonoloba reduced significantly with progressively increasing soil salinity stress, and this may be because of ion toxicity or indirect effect of osmotic imbalance between soil and plant caused by salt ions (Abdel-Latef, 2010). Also, the stunted plant growth under salt stress is normally occurred when high salt contents in soil prevent cell division directly or indirectly (Singh and Chatrath, 2001). However, mycorrhizal inoculation mitigated dry matter reduction in test plants under each salinity level as compared to respective nonmycorrhizal plants. Similar type of results were obtained in previous reports in which AM fungi improved plants dry biomass under salinity stress (Al-Karaki and Hammad, 2001; Gharineh et al., 2009). Present study indicated that individual mycorrhizal inoculation significantly improved dry matter accumulation in test plants as compared to respective non-mycorrhizal plant, but co-inoculation was found to be superior in this respect under salinity stress. It is already known that AM fungi are able to adapt edaphic environmental conditions and isolates from saline soil would have a better salt tolerance capacity (Copeman et al., 1996; Kaya et al., 2009). In our study, $G m$ was isolated from saline soil as a dominant spore and showed a greater positive response than the other isolate $(G f)$, but both of these worked better in co-inoculation treatment. Although, mycorrhizal inoculation resulted in enhanced dry weight in both the test plants, but, magnitude of dry weight increment due to mycorrhization was found better in $G$. max. Better growth of mycorrhizae treated plants has been correlated with more nutrient acquisition in AM mediated plants (Plenchette and Dupponois, 2005).

In the present study, increasing soil salinity gradually reduced chlorophyll content of mycorrhizae inoculated and uninoculated test plants. This result is in agreement with previous report where chlorophyll content in maize plant was declined under saline stress (Sheng et al., 2008). The reduction in chlorophyll content at higher salinity level is mainly because of suppression of chlorophyll synthesizing enzyme activity and less uptake of magnesium ion by plants (El-Desouky and Atawia, 1998; Murkute et al., 2006). But mycorrhizal inoculation can alleviate this problem to some extent and in our study, at each salinity level, significantly higher chlorophyll content was detected in leaves of G. max and C. tetragonoloba plants as compared with respective nonmycorrhizal plants. Thus, $G m$ and $G f$ association (individually and in combination) enhanced the photosynthetic ability of $G$. max and C. tetragonoloba under salinity stress, which is in agreement with earlier report (Sonnazzaro et al., 2006). Data from present study indicated that, regardless of host plant, maximum chlorophyll accumulation occurred by AM fungi in coassociation as compared to their individual association. At each soil salinity level leaves of $C$. tetragonoloba showed better chlorophyll accumulation as compared to G. $\max$.

When plants grow under saline conditions several types of salt stress proteins accumulate in plant to maintain osmotic balance, act as storage form of nitrogen and furthermore they can be re-utilized later once stress is over (Singh et al., 1987). In the present study, protein content followed an increasing trend at low range of salt stress however, higher soil salinity significantly reduced soluble protein contents in G. max and C. tetragonoloba plants irrespective of mycorrhizal inoculations. However at each salinity level protein content was improved significantly after mycorrhizal colonization as compared to corresponding non-mycorrhizal plants, even though maximum protein accumulation was observed in coinoculated test plants. Reduction in protein concentration with increasing soil salinity was observed, because salt stress interferes with nitrogen acquisition and utilization by interrupting protein synthesis (Aslam et al., 1984; Frechill et al., 2001). In present study, mycorrhizal inoculation mitigated the reduction in protein content in plants grown under saline gradient $(2.10$ to $8.26 \mathrm{dS} / \mathrm{m})$ and control $(1.04 \mathrm{dS} / \mathrm{m})$ treatment and may be because extra radical mycelia of AM fungi easily takes up inorganic nitrogen and transports it to intra radical mycelia. Hence, nitrogen can be easily transferred from fungus to plant in AM association (Govindarajulu et al., 2005). Moreover, percentage accumulation of soluble protein was found maximum in C. tetragonoloba plant, followed by G. max. This finding might be related to the fact that specific nitrogen containing compound accumulate in varying concentration in different plant species under salinity stress (Rabie and Almadini, 2005).

In this study, plants exposed to lower level of salt stress $(1.04$ to $3.78 \mathrm{dS} / \mathrm{m}$ ) contained better carbohydrate content than the plants exposed at higher salt stress and may be because of the fact that, in response to soil salinity, soluble carbohydrates have been proved to accumulate in plants to adjust osmotic potential and also serving as a carbon storage compound (Murakeozy et al., 2003; Parvaiz and Satyawati, 2008). Soluble carbohydrate contents of both the test plants were reduced significantly at higher level of salinity stress. However, mycorrhization in all the test plants significantly improved soluble carbohydrate contents compared to respective non-mycorrhizal plants exposed to control $(1.04 \mathrm{dS} / \mathrm{m})$ and soil salinity stress (2.10 to $8.26 \mathrm{dS} / \mathrm{m}$ ). It was also observed that better carbohydrate accumulation was achieved by combined AM inoculation irrespective of plant species. The positive correlation between mycorrhization of host plant and soluble sugar accumulation was also reported earlier (Al-Garni, 2006; Datta and Kulkarni, 2013). When both the test plants are compared, C. tetragonoloba plant accumulated better carbohydrate than G. max plant.

Increasing soil salinity (upto $3.78 \mathrm{dS} / \mathrm{m}$ ) enhanced the content of reducing sugar in test plants and this may 
be due to accumulation of several osmolytes (reducing sugar) in plants to remove osmotic disturbance which comes into effect under salt stress and this accumulated reducing sugar also acts as carbon storage (Parida and Das, 2005). Increment in reducing sugar content in various plant species (wheat, grapevine) has already been reported when they were exposed to salt stress (Kerepesi and Galiba, 2000; Khatkar and Kuhad, 2000, Singh et al., 2000). But mycorrhizal inoculations increased reducing sugar accumulation in test plants over the nonmycorrhizal plants at various soil salinity levels. Mycorrhizal inoculations with $G m$ and $G f$ isolates adjust osmotic balance in a better way and may help in higher osmo-protection.

With increasing soil salinity consistent increase in proline content in both the test plants (mycorrhizal and non-mycorrhizal treated) was observed. Under salinity stress exposure, proline (the protective osmolyte) accumulates for adaptation of salt stress, maintains osmotic balance and also acts as energy and nitrogen reservoir to be used by plant (Ashraf and Foolad 2007; Jindal et al., 1993). It was observed that, mycorrhizal treatment significantly improved proline concentration and their accumulation as compared to non-mycorrhizal plant under increasing soil salinity stress gradient. But a maximum proline accumulation was observed in cocolonized plant. More proline accumulation after AM colonization has already been reported earlier (Jindal $e t$ al., 1993). Better proline accumulation in $C$. tetragonoloba may be correlated with fact that more proline accumulates in less salt tolerant plant as a symptom of stress for maintaining osmotic adjustment (Wang et al., 2004).

Data of present study clearly indicate that electrolyte leakage can be positively correlated with provided salinity stress. In all the test plants, by increasing stress level $(2.10$ to $8.26 \mathrm{dS} / \mathrm{m}$ ), a significant reduction in electrolyte leakage was observed in AM inoculated G. max and $C$. tetragonoloba plants as compared to non-mycorrhizal plants. Less electrolyte leakage in mycorrhizae treated test plants may be correlated with higher electrolyte concentration in AM plants and this helps to maintain membrane stability (Garg and Manchanda, 2008). Mycorrhization in host plants is responsible for lowering electrolyte leakage at 2.10 to $8.26 \mathrm{dS} / \mathrm{m}$ soil salinity stress and this finding is in agreement with the other report (He et al., 2007).

Root colonization percentage was reduced significantly in mycorrhizae treated test plants, when salinity level was increased gradually. At each stress level, Gf inoculated plants had the least colonization percentage, however, $G m$ and co-inoculation with both AM fungi colonized the test plants roots in higher amount. The reduction in magnitude of percentage colonization under increasing salt stress might be due to inhibition of AM spore germination, interruption in hyphal growth in soil or reduction in arbuscule formation etc. (Hirrel, 1981; McMillen et al., 1998; Pfeiffer and Bloss, 1988). Between the two test plants, percentage of mycorrhizal colonization (by individual isolate and in combination) was found to be higher in $C$. tetragonoloba than G. max under various levels of salt stress $(2.10$ to $8.26 \mathrm{dS} / \mathrm{m})$ and control treatment $(1.04$ $\mathrm{dS} / \mathrm{m})$. More percentage of AM root colonization (individually and in combination) in C. tetragonoloba plant may be responsible for better accumulation of total chlorophyll, proline, carbohydrate contents etc. under salt stress and protected C. tetragonoloba plant from detrimental effect of salt stress in a better way.

\section{Conclusion}

G. mosseae and G. fasciculatum symbiotic interaction (as individually and in combination) with G. max and $C$. tetragonoloba plants, alleviated the deleterious effect of salt stress by improving various biochemical parameters. Even though, individual AM fungi showed positive effect in mitigation of salt effect, but co-inoculation with both $G m$ and $G f$ isolates worked better in this respect. Out of the two test plants, C. tetragonoloba showed better growth profile as compared to G. max in response to coinoculation by both the AM isolates under salt stress. Mycorrhization reduced electrolyte leakage profoundly and could maintain osmotic balance by stabilizing membrane stability. Hence, these two AM fungi can be further utilized as bio-inoculant in salt affected soils.

\section{Acknowledgements}

Authors express sincere thanks to Department of Biotechnoloy, New Delhi, India and University of Pune for the financial support.

\section{References}

Abdel Latef AA (2010). Changes of antioxidative enzymes in salinity tolerance among different wheat cultivars. Cereal Res Comm 38:43-55.

Al-Garni SMS (2006). Increasing NaCl-salt tolerance of a halophytic plant Phragmites australis by mycorrhizal symbiosis. Am Eurasian J Agric Environ Sci 1:119-126.

Al-Karaki GN (2000). Growth of mycorrhizal tomato and mineral acquisition under salt stress. Mycorrhiza 10:51-54.

Al-Karaki GN, Hammad R, Rusan M (2001). Responses of two tomato cultivars differing in salt tolerance to inoculation with mycorrhizal fungi under salt stress. Mycorrhiza 11:43-47.

Al-Karaki GN, Hammad R (2001). Mycorrhizal influence on fruit yield and mineral content of tomato grown under salt stress. J Plant Nut 24:1311-1323.

Allen MF (1991). The ecology of mycorrhizae. Cambridge University Press, New York, p. 82.

Ashraf M, Foolad MR (2007). Roles of glycine betaine and proline in improving plant abiotic stress resistance. Environ Exp Bot 59:206-216.

Aslam M, Huffaker RC, Rains DW (1984). Early effects of salinity on nitrate assimilation in barley seedlings. Plant Physiol 76:321-325. 
392

Augé RM (2000). Stomatal behaviour of arbuscular mycorrhizal plants, p. 201-237. In: Kapulnik Y and Douds DD (Eds.). Arbuscular mycorrhizas: physiology and functions. Kluwer Academic Publishers, Drodrecht.

Azcon-Aguiler C, Azcon R, Barea JM (1979). Endomycorrhizal fungi and Rhizobium as biological fertilizers for Medicago sativa in normal cultivation. Nature 279:325-327.

Bates LS, Waldren RP, Teare ID (1973). Rapid determination of free proline for water stress studies. Plant Soil 39:205207.

Bradford MM (1976). A rapid and sensitive method for the quantification of microgram quantities of protein utilizing the principle of protein-dye binding. Anal Biochem 72:248-254.

Burke DJ, Hamerlynck EP, Hahn D (2003). Interactions between the salt marsh grass season Spartina patens, arbuscular mycorrhizal fungi and sediment bacteria during the growing. Soil Biol Biochem 35:501-511.

Chartzoulakis K, Klapaki G (2000). Responses of two green house pepper hybrids to $\mathrm{NaCl}$ salinity during different growth stages. Sci Hortic 86:247-260.

Copeman RH, Martin CA, Stutz JC (1996). Tomato growth in response to salinity and mycorrhizal fungi from saline and non saline soil. HortSci 31:341-344.

Cuartero J, Fernandez-Munoz R (1998). Tomato and salinity. Sci Hortic 78:83-125.

Datta P (2012). Studies on the effect of arbuscular mycorrhizal fungi on some plants under salinity stress. Univ. of Pune, Pune, PhD Diss. 64-231.

Datta P, Kulkarni M (2013). Growth response and dependency of Arachis hypogaea L. on two AM fungi under salinity stress. Indian J Agric Biochem 26:18-24.

Dionisio-Sese ML, Tobita S (1998). Antioxidant responses of rice seedlings to salinity stress. Plant Sci 135:1-9.

El-Desouky SA, Atawia AAR (1998). Growth performance of Citrus rootstock under saline conditions. Alexandria J Agr Res 43:231-254.

Frechill S, Lasa B, Ibarretxe L, Lamsfus C, Aparicio Trejo P (2001). Pea response to saline stress is affected by the source of nitrogen nutrition (ammonium or nitrate). Plant Growth Regul 35:171-179.

Garg N, Manchanda G (2008). Effect of arbuscular mycorrhizal inoculation of salt-induced nodule senescence in Cajanus cajan (pigeon pea). J Plant Growth Regul 27:115-124.

Gerdemann JW, Nicolson TH (1963). Spores of mycorrhizal Endogene species extracted from soil by wet sieving and decanting. Trans Br Mycol Soc 46:235-244.

Gharineh MH, Nadian H, Fathi G, Siadat A, Maadi B (2009). Role of arbuscular mycorrhizae in development of salt tolerance of Trifolium alexandrinum plants under salinity stress. J Food Agric Environ 7:432-437.

Giovannetti M, Mosse B (1980). An evaluation of techniques for measuring vesicular-arbuscular mycorrhizal infection in roots. New Phytol 84:489-500.

Govindarajulu M, Pfeffer PE, Jin H, Abubaker J, Douds DE, Allen JW, Bücking H, Lammers PJ, Shachar-Hill Y (2005). Nitrogen transfer in the arbuscular mycorrhizal symbiosis. Nature 435:819-823.

Hamdy A (1990). Management practices under saline water irrigation. Symposium on scheduling of irrigation for vegetable crops under field conditions. Acta Hort 278:745754.

Hamdy A (1990). Saline irrigation practices: Leaching management. Proc water and waste water, '90' Conference, Barcelona, Spain, p. 10.

He Z, He C, Zhang Z, Zou Z, Wang H (2007). Changes of antioxidative enzymes and cell membrane osmosis in tomato colonized by arbuscular mycorrhizae under $\mathrm{NaCl}$ stress. Colloids Surf B 59:128-133.

Hedge JE, Hofreiter BT (1962). Carbohydrate Chemistry, p. 17. In: Wistler RL and Be Miller JN (Eds.). Academic Press, New York.

Hirrel MC (1981). The effect of sodium and chloride salts on the germination of Gigaspora margarita. Mycology 73:610617.

Hoagland DR, Arnon DI (1940). Crop production in artificial culture solutions and in soils with special reference to factors influencing yield absorption of inorganic nutrients. Soil Sci 50:463-484.

Hopkins WG, Huner NPA (1999). Introduction to plant physiology. Wiley, New York.

Jindal V, Atwal A, Sekkhon BS, Singh R (1993). Effect of vesicular-arbuscular mycorrhizae on metabolism of moong plants under $\mathrm{NaCl}$ salinity. Plant Physiol Biochem 31:475481.

Juniper S, Abbott LK (1993). Vesicular-arbuscular mycorrhizas and soil salinity. Mycorrhiza 4:45-57.

Kaya C, Ashraf M, Sonmez O, Aydemir S, Tuna AL, Cullu MA (2009). The influence of arbuscular mycorrhizal colonization on key growth parameters and fruit yield of pepper plants grown at high salinity. Sci Hortic 121:1-6.

Kerepesi I, Galiba G (2000). Osmotic and salt stress induced alteration in soluble carbohydrate content in wheat seedlings. Crop Sci 40:482-487.

Khatkar D, Kuhad MS (2000). Short-term salinity induced changes in two wheat cultivars at different growth stages. Biol Plant 43:629-632.

Lindermann RG (1994). Role of VAM in biocontrol, p. 1-26. In: Pfleger FL and Linderman RG (Eds.). Mycorrhizae and Plant Health. St. Paul: American Phytopathological Society.

McMillen BG, Juniper S, Abbott LK (1998). Inhibition of hyphal growth of a vesicular-arbuscular mycorrhizal fungus in soil containing sodium chloride limits the spread of infection from spores. Soil Biol Biochem 30:1639-1646.

Miller GL (1972). Use of DNS reagent for the determination of glucose. Anal Chem 31:426-428.

Murakeozy EP, Nagy Z, Duhazé C, Bouchereau A, Tuba Z 
(2003). Seasonal changes in the levels of compatible osmolytes in three halophytic species of inland saline vegetation in Hungary. J Plant Physiol 160:395-401.

Muralev E, Nazarenko PI, Poplavskij VM, Kuznetsov IA (1997). Seawater desalinization, p. 355-366. In: Nuclear desalinization of seawater. Proceedings of a symposium in Taejon, Republic of Korea, International Atomic Energy Agency, Austria, Vienna.

Murkute AA, Sharma S, Singh SK (2006). Studies on salt stress tolerance of citrus rootstock genotypes with arbuscular mycorrhizal fungi. Hort Sci 33:70-76.

Parida AK, Das AB (2005). Salt tolerance and salinity effects on plants; a review. Ecotox Environ Safe 60:324-349.

Parvaiz A, Satyawati S (2008). Salt stress and phytobiochemical responses of plants - a review. Plant Soil Environ 54:89-99.

Pfeiffer CM, Bloss HE (1988). Growth and nutrition of guayule (Parthenium argentatum) in a saline soil as influenced by vesicular-arbuscular mycorrhiza and phosphorus fertilization. New Phytol 108:315-321.

Phillips JM, Hayman DS (1970). Improved procedures for clearing root and staining parasitic and vesicular-arbuscular mycorrhizal fungi for rapid assessment of infection. Trans Br Mycol Soc 55:158-161.

Plenchette C, Duponnois R (2005). Growth response of the saltbush Atriplex numularia L. to inoculation with the arbuscular mycorrhizal fungus Glomus intraradices. J Arid Environ 61:535-540.

Porcel R, Ruiz-Lozano JM (2004). Arbuscular mycorrhizal influence on leaf water potential, solute accumulation and oxidative stress in soybean plants subjected to drought stress. J Exp Bot 55:1743-1750.

Rabie GH, Almadini AM (2005). Role of bioinoculants in development of salt-tolerance of Vicia faba plants under salinity stress. Afr J Biotechnol 4:210-222.

Ruiz-Lozano JM (2003). Arbuscular mycorrhizal symbiosis and alleviation of osmotic stress: New perspectives for molecular studies. Mycorrhiza 13:309-317.

Sadik N (1991). Population growth and the food crisis: food, nutrition and agriculture/alimentation. Nut Agr 1:3-6.

Schenck NC, Perez Y (1990). Manual for the identification of VA Mycorrhizal fungi, 3rd Ed. Synergistic Publications, Gainesville, Florida.

Sheng M, Tang M, Chen H, Yang B, Zhang F, Huang Y (2008). Influence of arbuscular mycorrhizae on photosynthesis and water status of maize plants under salt stress. Mycorrhiza 18:287-296.
Singh SK, Sharma HC, Goswami AM, Datta SP, Singh SP (2000). In vitro growth and leaf composition of grapevine cultivars as affected by sodium chloride. Biol Plantarum 43: 283-286.

Singh KN, Chatrath R (2001). Salinity Tolerance, p. 101-110. In: Reynolds MP, Monasterio JIO and McNab A (Eds.). Application of Physiology in wheat breeding. CIMMYT, Mexico, DF.

Singh NK, Bracker CA, Hasegawa PM, Handa AK, Buckel S, Hermodson MA, Pfankoch E, Regnier FE, Bressan RA (1987). Characterization of osmotin. A thaumatin-like protein associated with osmotic adaptation in plant cells. Plant Physiol 85:529-536.

Sonnazzaro AI, Ruizn OA, Edgardo OA, Mendez AB (2006). Alleviation of salt stress in Lotus glaber by Glomus intraradices. Plant Soil 285:279-287.

Strain HH, Svec WA (1966). Extraction, separation, estimation and isolation of chlorophylls, p. 21-66 In: Vernon LP and Seely GR (Eds.). Academic Press.

Sylvia DM, Williams SE (1992). Vesicular-arbuscular mycorrhizae and environmental stress, p. 101-124. In: Bethlenfalvay GJ and Linderman RG (Eds.). Mycorrhizae in sustainable agriculture. American Society of Agronomy, Special Publ. No. 54, Madison..

Tian CY, Feng G, Li XL, Zhang FS (2004). Different effects of arbuscular mycorrhizal fungal isolates from saline or nonsaline soil on salinity tolerance of plants. Appl Soil. Ecol 26:143-148.

Wang S, Wan C, Wang Y, Chen H, Zhou Z, Fu H, Sosebee RE (2004). The characteristics of $\mathrm{Na}^{+}, \mathrm{K}^{+}$and free proline distribution in several drought-resistance plants of the Alxa Desert, China. J Arid Environ 56:525-539.

Weaver LT (1994). Feeding the weanling in the developing World: Problems and solutions. Int J Food Sci Nut 45:127-134. 